\title{
Analysis of Latent Factors Underlying Conceptions of People with Dementia and the Effects of Social Resources
}

\author{
Ippei Kawasaki ${ }^{1,2}$, Shun Harada ${ }^{1}$, Kuniaki Nagai ${ }^{1}$, Noriyuki Ogawa ${ }^{1,3}$, Hajime Takechi ${ }^{3,4}$, Naoko \\ Hara $^{3,5}$, Kyoko Eguchi ${ }^{3,6}$ and Kazuo Kariyama ${ }^{3,7}$ \\ ${ }^{1}$ Kyoto Tachibana University, Japan \\ ${ }^{2}$ Graduate School of Science and Technology, Shizuoka University, Japan
}

${ }^{3}$ Alzheimer's Association Japan, Japan

${ }^{4}$ Fujita Health University, Japan

${ }^{5}$ Niigata College of Nursing, Japan

${ }^{6}$ Shumei University, Japan

${ }^{7}$ Yassa Koubou Nishimachi, Japan

*Corresponding author: Ippei Kawasaki, Kyoto Tachibana University, 34 Yamada-cho Oyake, Yamashina-ku, Kyoto 607-8175, Japan

\section{ARTICLE INFO}

Received: 幽 September 22, 2021

Published: 㓞 October 05, 2021

Citation: Ippei Kawasaki, Shun Harada, Kuniaki Nagai, Noriyuki Ogawa, Hajime Takechi, et al., Analysis of Latent Factors Underlying Conceptions of People with Dementia and the Effects of Social Resources. Biomed J Sci \& Tech Res 39(2)2021. BJSTR. MS.ID.006271.

Keywords: Dementia; Person-Centred Care; Stigma; Factor Analysis; Symbiosis

\section{ABSTRACT}

Background: As policies aimed at deepening the understanding of dementia have become a global issue, to reduce the stigma of the condition and to realize a society of symbiosis, we will clarify the conceptions that the general public have about people with dementia. We will also examine the effects that existing initiatives and social resources have on public understanding of people with dementia.

Methods: In this study, we prepared 18-item questionnaire polling respondents' conceptions of people with dementia and conducted an attitude survey using this questionnaire among 12,410 citizens. Using our obtained data, we extracted the latent factors that make up the conceptions of people with dementia through exploratory factor analysis. Further, we ascertained whether respondents had attended dementia supporter training courses, the extent of their knowledge of social resources related to dementia, and their level of experience with people with dementia. We tracked differences in factor scoring to examine how these factors contributed to positive conceptions of people with dementia.

Results: As a result of our factor analysis, we extracted the following factors as making up conceptions of people with dementia - Factor I: Person-centredness, Factor II: Behavioral and psychological symptoms of dementia, Factor III: Forgetfulness, and Factor IV: Unknown anxiety. Further, we found that the group that had attended dementia supporter training courses, the group that was highly aware of social resources such as long-term care insurance, dementia cafés, and supporter groups, and individuals who had frequent opportunities to interact with people with dementia all had significantly higher factor scores for Factor I, Person-centredness.

Discussion: In Japan, positive and negative conceptions of people with dementia often exist alongside one another. To reduce stigma and encourage person-centredness, it is important to provide opportunities to learn about dementia, to spread awareness of social resources, and to interact with people with dementia. 


\section{Introduction}

Against the backdrop of Japan's fast-declining birth rate and growing-ageing population, support measures for people with dementia, estimated to be around 7 million in 2025, are drawing attention. In the Dementia Policy Promotion Outline promulgated by the Ministry of Health, Labour and Welfare in June 2019, 'symbiosis' is listed as a pillar, and 'dissemination and enlightenment / personal dissemination support' is listed as Factor 1 in the section on specific measures [1]. This can be interpreted as a message that we must deepen our understanding of dementia to ensure that people with dementia and their families can continue living in their own way in their communities. Globally, many OECD countries have designated the promotion of dementia awareness as a preeminent national strategy for supporting dementia. In the 2019 World Alzheimer Report released by the International Association for Alzheimer's Disease, the need to reduce stigma for people with dementia was strongly emphasized, and 10 recommendations were proposed [2]. These recommendations include the creation of communities that are kind to people with dementia and to practice person-centred care. In other words, these recommendations encourage people to cultivate positive conceptions about dementia, and countries throughout the world are being asked to create policies that deepen understanding and awareness of the condition.

\section{Person-Centred Care \& Stigma}

A positive keyword for dementia understanding and awareness is 'person-centred care', and a negative keyword is 'stigma'. The former is a concept proposed in the 1990s by Dr Tom Kitwood of the University of Bradford, England, which advocates for a reimagining of our conception and perception of dementia, based primarily on traditional medical models of the condition, and instead emphasizes respect of the 'personhood' of people with dementia, a quality encompassing the entirety of their personality. Based on this concept of 'person-centeredness', Dr Kitwood listed five simple items as the emotional needs of a people with dementia: comfort, identity, occupation, inclusion, and attachment [3]. Brooker lists the four elements of person-centered care: valuing people (acknowledging the worth and value of a person's existence), individualized care (respecting a person's individuality), personal perspective (looking at the world from that person's perspective), and social environment (providing a social environment to support the dementia-affected individual) [4]. Person-centredness goes beyond the medical/caregiving setting and is a concept useful for broadly deepening the understanding of dementia; it serves as a base for helping community individuals understand the lives and circumstances of people with dementia.

On the other hand, one of the primary factors hindering understanding of dementia is 'stigma'. Byrne describes stigma as a discriminatory attitude toward or negative outlook on the conspicuous or unusual characteristics or traits of individuals [5]. The World Alzheimer Report 2019 cites the existence of stigmas as a major obstacle to both the provision of dementia-related information to those that seek it and the delivery of care and support to those that need it [2]. In the 2013 'G8dementia Summit', the $11^{\text {th }}$ item of the Global Action against Dementia agenda was the strengthening of efforts to lessen stigma towards dementia [6]. Kudo has conducted analyses of stigmas toward people with dementia in Japan and pointed out that when it comes to supporting them, their surrounding environment-especially their relationships with other individuals-is particularly important, and that stigma serves as an obstacle to early community detection of and intervention for people with dementia [7]. In the same paper, Kudo lists behavioural impairment among people with dementia, lack of knowledge of the condition itself, and anxieties about one's own future condition as factors connected to dementia-related stigma. Removing these stigmas is not an easy task. Since they are often rooted in the history and culture of a nation or region, rather than proposing sweeping policies to counteract dementia-related stigma, the idea of stigma reduction itself should be hoisted as a global directive, and communities should work at the local level to encourage and deepen dementia awareness.

\section{Hypothesis and Study Purpose}

The two opposing concepts described above represent the opposite ends of the spectrum upon which our conceptions of people with dementia as an illness and our attitudes and expectations when confronting the condition lie. Philipson's research team at Wollongong University has created a scale to holistically capture individuals' stigmas toward dementia, which are classified into the following three categories: Isolation and avoidance of individuals with dementia, Positive perceptions of people with dementia, and Conceptions of oneself if one were to develop dementia; this scale reveals that both positive and negative aspects are involved in conceptions of condition [8]. Further, Philipson etal. (2014) targeted 616 people in Australia to derive four latent concepts that comprise conceptions of dementia in the Australian public: Avoidance, Fear of labelling, Fear of discrimination, and Person-centredness [9]. Thus, scales meant to measure stigma toward dementia and the results of analyses of latent factors have revealed that person-centredness and stigma are key factors affecting dementia understanding. We can, therefore, hypothesize that in Japan too, conceptions of people with dementia are made up of these sorts of positive and negative elements.

In 2019, the Alzheimer's Association Japan (AAJ) carried out a 'Survey of Feelings of People with Dementia and their Families, Care Status, and Public Attitudes towards Dementia'. In this study, 
we used the results of the "Survey of General Public Attitudes toward Dementia," which was part of that survey, to conduct our analysis. As we test the aforementioned hypothesis, the objective of this study is to clarify the conceptions of people with dementia and to ascertain how existing initiatives and social resources affect dementia understanding and awareness among the general public.

\section{Materials and Methods}

The details of the attitude survey (questionnaire format) used in this study are provided below.

\section{Questionnaire Survey Procedure}

With the cooperation of AAJ chapters in the 47 administrative districts of Japan, the survey was carried out by targeting attendees and participants of public events held by each chapter, including lectures, university festivals, community events, elderly persons' clubs, and dementia cafés. The survey was administered by AAJ staff members, and staff members/research collaborators periodically collected responses and sent them back to the main research office. Further, the survey was also uploaded to the AAJ website, distributed via a bulletin and related organizations, and implemented as a web survey. At lecture sessions, to prevent the content of lectures, etc., from influencing participant answers, the surveys were distributed and filled out prior to the event itself. These surveys were conducted between June 1 and November 15, 2019. The attitude survey conducted in this study was carried out anonymously, and no questions that would allow anyone to ascertain the identity of the respondent were set forth. Respondents were provided with an explanation of the objectives behind the survey and were told that the survey itself and analyses of the results would be exhibited to the country and the public and that responding to the survey would be deemed to provide consent to participate. This study was carried out with the approval of the Alzheimer's Association Japan's Ethics Committee (approval no. 2019-2003). The authors declare no conflicts of interest.

\section{Content of Attitude Survey}

The attitude survey polled respondents on their basic attributes (age, sex, place of residence, occupation), connections with people with dementia, conceptions of people with dementia (18 items), and use and knowledge of social resources (dementia supporter training courses, long-term care insurance, dementia cafés, and AAJ). The 18-item questionnaire on conceptions of people with dementia was formulated after referencing similar material by the Cabinet Office [10], Saitama Prefecture [11], Sugihara [12], Hirotani [13], and Yamada [14] (Table 1). Participants were asked to respond to the following question items using a 4-point scale (1. Agree 2. Somewhat agree 3. Somewhat disagree 4. Disagree).
Table 1: 18 Questions on Conceptions of People with Dementia.

\begin{tabular}{|c|c|}
\hline 1 & I think dementia is a disease of forgetfulness. \\
\hline 2 & $\begin{array}{l}\text { I think dementia is a disease where people constantly ask others } \\
\text { the same questions. }\end{array}$ \\
\hline 3 & I think dementia is a disease that causes puzzling behaviour. \\
\hline 4 & I think dementia is a disease that causes people to wander. \\
\hline 5 & I think dementia is a disease that causes people to get angry easily. \\
\hline 6 & $\begin{array}{l}\text { I think people suffering from dementia become unable to care for } \\
\text { themselves. }\end{array}$ \\
\hline 7 & Dementia is unpreventable. \\
\hline 8 & I don't understand what kind of disease dementia is. \\
\hline 9 & $\begin{array}{l}\text { I think the cause of dementia is a breakdown of the balance } \\
\text { between one's mind and body. }\end{array}$ \\
\hline 10 & I think anyone can develop dementia. \\
\hline 11 & I have thought about what would happen if I developed dementia. \\
\hline 12 & $\begin{array}{c}\text { Understanding by surrounding people is very important in } \\
\text { dementia. }\end{array}$ \\
\hline 13 & $\begin{array}{l}\text { It is good for people with dementia to participate in community } \\
\text { activities. }\end{array}$ \\
\hline 14 & $\begin{array}{l}\text { It is possible to share happiness and enjoyment with people with } \\
\text { dementia. }\end{array}$ \\
\hline 15 & $\begin{array}{l}\text { People with dementia has ups and downs, and when "up," they can } \\
\text { live normally. }\end{array}$ \\
\hline 16 & $\begin{array}{l}\text { It is important to be lenient with people with dementia listen to } \\
\text { what they have to say. }\end{array}$ \\
\hline 17 & $\begin{array}{l}\text { People with dementia are often in a state of mental turmoil or } \\
\text { anxiety. }\end{array}$ \\
\hline 18 & $\begin{array}{l}\text { People with dementia are probably optimistic and not much } \\
\text { trouble. }\end{array}$ \\
\hline
\end{tabular}

\section{Analysis}

A total of 12,410 individuals responded to the questionnaire (556 completed it online). Of these, 10,485 individuals responded to all 18 items regarding conceptions of people with dementia. These 10,485 responses were, therefore, used as the analysis set for this study. In this study, the results of our attitude survey of conceptions of people with dementia were analysed via exploratory factor analysis and tests of mean differences. First, reverse-coded items for each of the 18 question items regarding conceptions of dementia were created, after which exploratory factor analysis (main factor method/Promax rotation) was carried out. At that time, items whose factor communality fell below 0.3 , were excluded from the analysis. Next, extracted factor loadings were used to group and name questionnaire items, and Cronbach's $\alpha$ coefficients were calculated to examine reliability (values $\geq 0.70$, indicating high internal validity). The validity of the factor analysis was confirmed by Kaiser-Meyer-Olkin's sample validity measure (determined to be valid at $\geq 0.5$ ) and Bartlett's sphere test. 
Further, to examine the effects that use or knowledge of social resources for dementia understanding and experience interacting with people with dementia had on the factor scores of factors comprising positive conceptions of dementia (extracted via exploratory factor analysis), we separated respondents into groups. First, we separated them into two groups based on whether or not they had taken a dementia supporter training course, as determined by responses to a question (1. Yes, I have, 2. No, I have not), and compared the mean factor score of Factor I between these groups. Next, we separated respondents into a high-awareness and lowawareness group based on their answers (1. Informed, 2. Somewhat informed, 3. Not very informed, 4. Uninformed) to each of the three questions about knowledge of long-term care insurance, Knowledge of dementia cafés, and Knowledge of AAJ; Individuals who answered 1 or 2 were placed into the high-awareness group, and those who answered 3 or 4 were placed into the low-awareness group. After doing so, we once again compared the mean factor scores of factors related to positive conceptions about dementia between groups for each question. Finally, for question item which asked participants about their level of experience in interacting with people with dementia, we sorted respondents into three groups based on their answers (Experienced, Somewhat experienced, No experience) and compared the mean factor scores for Factor I between groups using a one-way analysis of variance. Statistical analyses were performed using the IBM SPSS Statistics Ver. 27.01 for Macintosh.

\section{Results}

The results of the attributes (age, gender, occupation) of the 10,485 analysed respondents are shown in (Table 2). The results of this survey tended to show a high percentage of pensioner and housewife/house husband due to the relatively high age range of the respondents, as well as a relatively high number of respondents in the medical and welfare professions, and this is described as a limitation of the study below. The responses to questions regarding attendance at dementia supporter training courses, awareness of social resources related to dementia (long-term care insurance services, dementia cafés, and AAJ), and experience with people with dementia are shown in (Table 3). The results of our exploratory factor analysis of answers to questions regarding conceptions of people with dementia are shown in (Table 4). The four items whose communality fell below 0.3 during the factor analysis process [question items (7), (9), (10), and (11)] were excluded. After extracting the factors for the remaining 14 items, four factors with initial eigenvalues greater than 1.0 were extracted (cumulative contribution rate 61.2\%). The Cronbach's $\alpha$ coefficient for these 14 items was 0.75 , confirming their internal validity.

Table 2: 18 Questions on Conceptions of People with Dementia.

\begin{tabular}{|c|c|c|c|c|c|}
\hline \multicolumn{2}{|c|}{ Age } & \multicolumn{2}{|c|}{ Gender } & \multicolumn{2}{|l|}{ Occupation } \\
\hline$<20$ years & 338 & Male & 2,856 & Student & 849 \\
\hline 20-29 years & 877 & Female & 7,521 & Company employee & 1298 \\
\hline 30-39 years & 880 & Other & 18 & Self-employee & 445 \\
\hline 40-49 years & 1,583 & No response & 90 & Part-time worker & 844 \\
\hline $50-59$ years & 1,985 & & & Pensioner & 2056 \\
\hline 60-69 years & 2,061 & & & Housewife/ Househusband & 2087 \\
\hline 70-79 years & 2,118 & & & Medical staff & 1297 \\
\hline$\geq 80$ years & 570 & & & (Dr, Ns, Dentist, Rehabilitation staff) & \\
\hline \multirow[t]{10}{*}{ No response } & 73 & & & Nutritionist & 38 \\
\hline & & & & Clerk & 80 \\
\hline & & & & Care manager & 921 \\
\hline & & & & Care worker & 816 \\
\hline & & & & Social worker & 392 \\
\hline & & & & Home help service staff & 160 \\
\hline & & & & Facility administrator & 161 \\
\hline & & & & Government officials & 387 \\
\hline & & & & Civil servant & 228 \\
\hline & & & & Other & 838 \\
\hline Total & 10,485 & Total & 10,485 & *multiple answers possible & \\
\hline
\end{tabular}


Table 3: Results of questionnaire on dementia supporter training course attendance, awareness of social resources, and experience interacting with people with dementia.

\begin{tabular}{|l|c|c|c|c|c|c|}
\hline \multirow{2}{*}{$\begin{array}{l}\text { Have you attended a dementia supporter training } \\
\text { course? }\end{array}$} & Yes, I have & $\begin{array}{c}\text { No, I have } \\
\text { not }\end{array}$ & No response & & \multirow{2}{*}{ Total } \\
\cline { 2 - 7 } & 4,331 & 5,903 & 251 & & 10,485 \\
\hline \multirow{2}{*}{$\begin{array}{l}\text { How informed are you about long-term care insurance } \\
\text { services for dementia? }\end{array}$} & Informed & $\begin{array}{c}\text { Somewhat } \\
\text { informed }\end{array}$ & $\begin{array}{c}\text { Not very } \\
\text { informed }\end{array}$ & Uninformed & No response & Total \\
\cline { 2 - 7 } & 4,420 & 2,843 & 2,225 & 794 & 203 & 10,485 \\
\hline How informed are you about dementia cafés? & 4,847 & 1,594 & 2,056 & 1,778 & 210 & 10,485 \\
\hline $\begin{array}{l}\text { How informed are you about the Alzheimer's } \\
\text { Association of Japan? }\end{array}$ & 4,499 & 1,540 & 2,521 & 1,723 & 202 & 10,485 \\
\hline \multirow{2}{*}{$\begin{array}{l}\text { How much experience do you have interacting with } \\
\text { people with dementia? }\end{array}$} & Experienced & $\begin{array}{c}\text { Somewhat } \\
\text { experienced }\end{array}$ & No experience & No response & & \multirow{2}{*}{ Total } \\
\cline { 2 - 7 } & 7,501 & 1,448 & 1,420 & 116 & & 10,485 \\
\hline
\end{tabular}

Table 4: Results of exploratory factor analysis on conceptions of people with dementia.

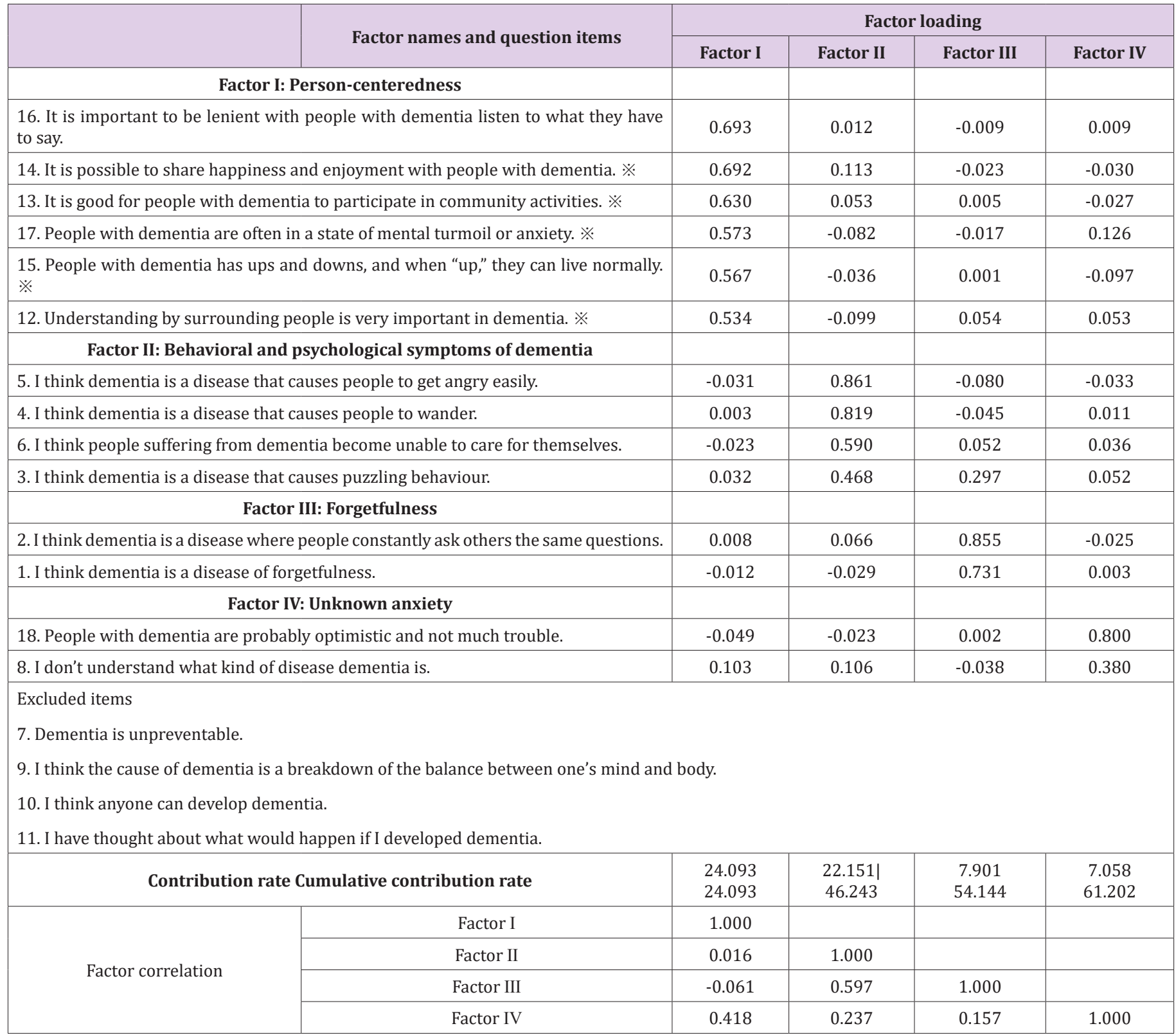

Note: Cronbach's a coefficient for all items: 0.745

Factor extraction method: main factor method / Promax rotation

※ Indicates reverse-coded factors 
The value for the Kaiser-Meyer-Olin sample validity test, which expresses the validity of the factor analysis, was 0.83 , and the result of the Bartlett sphere test was $p<0.00$, demonstrating that the analysis was valid overall. Based on the nature of the question items comprising each factor, the following names were chosen - Factor I: 'Person-centredness', Factor II: 'Behavioural and psychological symptoms of dementia', Factor III: 'Forgetfulness', and Factor 4: 'Unknown anxiety'. Next, we tested mean difference to determine whether the use/awareness of dementia-related social resources and experience interacting with people with dementia affected the factor score of Factor I, Person-centredness (hereafter referred to as PC score). In our analysis, the Levene test was performed to verify the homoscedasticity of each item. As a result, in this analysis, Welch's t-test was adopted to compare the two groups (four items), and Welch's test was also adopted for analysis of variance among the three groups (one item). First, a significant difference in mean PC score was observed between the two groups: Had and had not attended a dementia supporter training course. Significant differences were also observed for high- and low-awareness groups for long-term care insurance awareness, Dementia café awareness, and AAJ awareness. Finally, a one-way ANOVA test between the three groups divided by (5) level of experience with people with dementia also revealed significant differences. The results are presented in (Table 5).

Table 5: The effects of use/awareness of social resources and level of experience interacting with people with dementia have on PC score.

\begin{tabular}{|c|c|c|c|c|c|}
\hline & & Number & Mean & Std. error & t-value / F-value \\
\hline \multirow{3}{*}{$\begin{array}{c}\text { History of attendance at dementia supporter } \\
\text { training courses }\end{array}$} & Overall & 10,234 & 0.006 & 0.009 & \multirow{3}{*}{$32.483^{*}$} \\
\hline & Have attended & 4,331 & 0.307 & 0.010 & \\
\hline & Have not attended & 5,903 & -0.214 & 0.013 & \\
\hline \multirow{3}{*}{ Awareness of long-term care insurance } & Overall & 10,282 & 0.004 & 0.009 & \multirow{3}{*}{$32.126^{*}$} \\
\hline & High-awareness & 7,263 & 0.197 & 0.009 & \\
\hline & Low-awareness & 3,019 & -0.462 & 0.019 & \\
\hline \multirow{3}{*}{ Awareness of dementia cafés } & Overall & 10275 & 0.005 & 0.009 & \multirow{3}{*}{$35.242^{*}$} \\
\hline & High-awareness & 6,441 & 0.247 & 0.009 & \\
\hline & Low-awareness & 3,834 & -0.402 & 0.016 & \\
\hline \multirow{3}{*}{ Awareness of Alzheimer's Association of Japan } & Overall & 10,283 & 0.005 & 0.009 & \multirow{3}{*}{$34.464^{*}$} \\
\hline & High-awareness & 6,039 & 0.256 & 0.009 & \\
\hline & Low-awareness & 4,244 & -0.354 & 0.015 & \\
\hline \multirow{4}{*}{$\begin{array}{l}\text { Level of experience interacting with people with } \\
\text { dementia }\end{array}$} & Overall & 10,369 & 0 & 0.009 & \multirow{4}{*}{ 513.713* } \\
\hline & Experienced & 7,501 & 0.186 & 0.009 & \\
\hline & Somewhat experienced & 1,448 & -0.375 & 0.0249 & \\
\hline & No experience & 1,420 & -0.598 & 0.029 & \\
\hline
\end{tabular}

Note: * $\mathrm{p}<0.001$

\section{Discussion}

\section{Conceptions of People with Dementia}

In this study, the first stage of our factor analysis revealed the compositional elements of conceptions of people with dementia in Japan. The factors extracted were as follows: Person-centeredness, Behavioral and psychological symptoms of dementia, Forgetfulness, and Unknown anxiety. The fact that our results resemble those of the analysis conducted by Philipson et al. insofar as 'Personcenteredness' was extracted as a latent factor in the positive understanding of dementia is of significant importance.

At the beginning of the 'Future Directions for Policies on Dementia' promulgated in 2012 by the Ministry of Health, Labor and Welfare, the history of cruel treatment of people with dementia, including ostracization and physical confinement, was outlined [15]. Furthermore, psychiatric hospitals and old-age homes have long served as receptacles for people with dementia. Miyazaki details how they have lived under horrible conditions and have been targets of discrimination [16]. However, in the 1980s, the acceptance of people with dementia into special nursing homes for the elderly began, and national qualifications for care workers and social workers who could play a central role in dementia care were developed. Since then, Alzheimer's disease International has set a policy of eradicating stigma worldwide, and various national measures for understanding dementia have been taken in Japan as well. 
The extraction of person-centeredness as the first among the latent factors that comprise conceptions of people with dementia is a sign that we are finally breaking away from our long history of treating people with dementia unfairly. We can believe it positively as a tolerant society that understands people with dementia is being fostered.

On the other hand, "II. Behavioural and psychological symptoms of dementia (BPSD)" and "III. Forgetfulness" factors were extracted, which means that negative conceptions of people with dementia persist. However, the fact that BPSD contributes to people's conceptions of people with dementia is not entirely negative; it can be interpreted as a natural consequence of the nature of the illness. Memory impairment is the most emblematic of dementia symptoms, and it is medically correct to state that the BPSD interfere with and impede activities of daily living (ADL). It is important to realize that BPSD is the result of cognitive decline and other impairments caused by degeneration of neurons and cerebral vasculature and that they prevent individuals from properly interacting and engaging with their surroundings, forcing them into a state of confusion. Once we understand this, an attitude of acceptance (sympathetic attitude) can be achieved.

It is also interesting that 'unknown anxiety' exists as a latent factor in the conceptions of people with dementia. While this can be interpreted as a negative factor, but this can be seen as a negative factor, but it is also a result of the information confusion that has surfaced as Japan faces the social challenge of an aging population. In our highly advanced information-oriented society, most media sources depict ageing as a problem to be solved. Identifying correct information and determining what people needs to understand is particularly difficult in modern society, in particular, individuals that do not normally interact with elderly persons can have limited opportunities to experience dementia proximally, and negative conceptions pushed by media narratives take precedence. Ogawa holds that a deep understanding and acceptance of people with dementia are necessary for the realization of an inclusive society (a 'dementia-friendly community') [17], and it is not difficult to imagine how 'unknown anxiety' could serve as an obstacle to such a goal. We hope that it will eventually become commonplace for individuals to be fully informed of and understand how to properly interact with them.

\section{Factors Affecting Positive Conceptions of Dementia}

The second stage of our factor analysis involved using tests of mean difference to analyse the effects of using and awareness of dementia-related resources and degree of experience interacting with people with dementia had on the PC score of Factor I as extracted by our exploratory analysis. All items polled at this stage of the questionnaire showed significant differences. First, we found that attending dementia supporter training courses improved the respondents' PC scores. Dementia supporter training courses are actively promoted in the Outline for Dementia Policy Promotion (2019) to encourage understanding of dementia, but, at the local level, there is much debate about regional differences in session content and the actual impact of the sessions themselves. While we will not touch upon the content of these courses here, we hope for further expansion of efforts to promote education for dementia understanding and empathy among individuals who live near people with dementia.

Awareness of long-term care insurance, dementia cafés, and AAJ also raised PC scores. The fundamental principle underlying long-term care insurance is not to simply serve the individual needing care or to attend to their needs, but to support their independence. This idea of supporting independence is similar to that of personhood as posited by Kitwood, and we can surmise that it should be possible for correct knowledge of long-term care insurance to improve PC scores. Participation in organizations that work with people with dementia and their families affords individuals opportunities to directly feel the difficulties that these individuals experience in their daily lives and the often invisible tribulations of a caregiving family. The best way to deepen one's sympathetic understanding is to listen to the voices of affected persons and their families.

Significant differences were also observed in our tests of mean PC scores (analysis of variance) across the three groups of individuals sorted according to their level of experience in interacting with people with dementia (1. Experienced, 2. Somewhat experienced, 3. No experience). Even outside of the realm of interactions with them, repeated experiences of anything acclimate one to it (normalization). This is a concept that most of us are quite familiar with. The Outline for Dementia Policy Promotion explains 'symbiosis' as 'allowing people with dementia to live with dignity and hope, even with their condition, and enabling all people to participate in society, regardless of whether or not they have dementia'. As we can see, encouraging understanding of dementia among the public and expanding opportunities for people to interact with people with dementia will foster a sense of personcentredness.

While determining how and when to set up these opportunities for both groups to interact with one another is a project for the future, unbiased information provision (education) that takes place before stigmas can take hold is necessary. We believe that the findings obtained through this study will be important for future policy considerations for promoting dementia understanding and awareness. Changing the stigmas in people's hearts to positive conceptions will undoubtedly lead to the early discovery of dementia and the realization of warm, personable care environments. Therefore, it will be necessary to continue to examine the meaning and impact of existing measures, such as dementia 
supporter training courses, and awareness-raising activities for understanding dementia in society in Japan. In addition, greater use of social resources aimed at dementia awareness or expanded educational efforts to teach individuals about people with dementia will help us understand the condition as one that is very proximal to all members of society, and will help grow a society rich in personcenteredness. Against such a backdrop, people with dementia will also have more opportunities to enter and engage with society, thereby growing person-centredness of people further. To truly realize a society of symbiosis with dementia, we must work to create a positive cycle that heightens our levels of person-centredness.

\section{Limitations of this Study and Future Issues}

The data we analysed in this study was based on a survey conducted at events where the elderly was relatively likely to participate, and some of the responses included those from medical and welfare professionals. Therefore, there was a possibility that some of the respondents already had an interest in dementia. Future research needs to understand the views of those who do not have preconceived notions about dementia in order to further explore the reality of stigma against people with dementia. In addition, since this study is a cross-sectional study, we cannot deny that there is a reverse causal relationship between the use and knowledge of social resources for dementia understanding and experience interacting with people with dementia raised PC scores. These points will be mentioned as limitations of this study at the end.

\section{Acknowledgment}

This paper analyses the results of the 'Survey of Feelings of People with Dementia and their Families, Care Status, and Public Attitudes towards Dementia" conducted by the Health Promotion Project for the Elderly subsidy. We would like to express our deepest appreciation to the Alzheimer's Association Japan main office, administrative office, and all employees of the branch offices that made this research possible. We would also like to extend our deep gratitude to everyone who answered the questionnaire.

ISSN: 2574-1241

DOI: 10.26717/BJSTR.2021.39.006271

Ippei Kawasaki. Biomed J Sci \& Tech Res

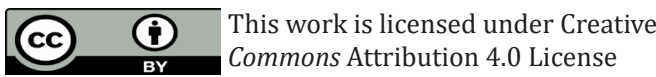

Submission Link: https://biomedres.us/submit-manuscript.php

\section{Disclosure}

The authors have no conflicts of interest directly relevant to the content of this article.

\section{References}

1. (2021) Ministry of Health, Labour and Welfare. Broad outline of policy measures against dementia.

2. (2019) Alzheimer's disease International. World Alzheimer Report 2019.

3. Kitwood T (1997) Dementia reconsidered; the person comes first. United Kingdom: open University press.

4. Brooker D (2015) Person-centred dementia care. United Kingdom: Jessica Kingsley Publishers.

5. Byrne P (2001) Psychiatric stigma. Br J Psychiatry 178 (3): 281-284.

6. (2021) Ministry of Health, Labour and Welfare. G8 Dementia Summit Declaration.

7. Kudo K (2017) Text analysis of care professionals' perspectives on dementia related stigma; based on data from interviews with care staff. Bulletin of Tohoku Fukushi University 41: 145-159.

8. Phillipson L, Magee CA, Jones S, Skladzien E (2012) Exploring dementia and stigma beliefs; a pilot study of Australian adults aged 40 to $65 \mathrm{yrs}$.

9. Phillipson L, Magee CA, Jones SC, Skladzien E (2014) Correlates of dementia attitudes in a sample of middle-aged Australian adults. Australas J Ageing 33(3): 158-163.

10. (2021) Government Public Relations. Overview of public opinion poll on dementia.

11. (2021) Saitama prefecture. Dementia: Public opinion poll on prefectural governments.

12. Sugihara Y, Yamada H, Takechi H (2005) Examining older adults' knowledge and images about dementia of alzheimer's type and their relation with other factors. Journal of Japanese Society for Dementia Care 4(1): 9-16.

13. Hirotani Y, Kawaguchi R, Urashima Y, Matsumoto C, Morimoto T, et al. (2019) Questionnaire survey on the pharmacy students' Attitudes and opinions following the dementia supporter education lecture. Japanese Society of Social Pharmacy 38(1): 14-19.

14. Yamada A (2007) Still underway to achieve "correct understanding"; from a telephone survey on dementia. The NHK monthly report on broadcast research 57(3): 38-47.

15. (2021) Ministry of Health, Labour and Welfare. The future direction of dementia.

16. Miyazaki W, Tanabe J (2011) Would you like to learn about the history of dementia? Japan: Chuohoki Publishing Co., Ltd.

17. Ogawa N, Donkai S, Nariai S (2017) Creation of Dementia Friendly SocialResources. Japanese Journal of Geriatric Psychiatry 28(5): 477-484.

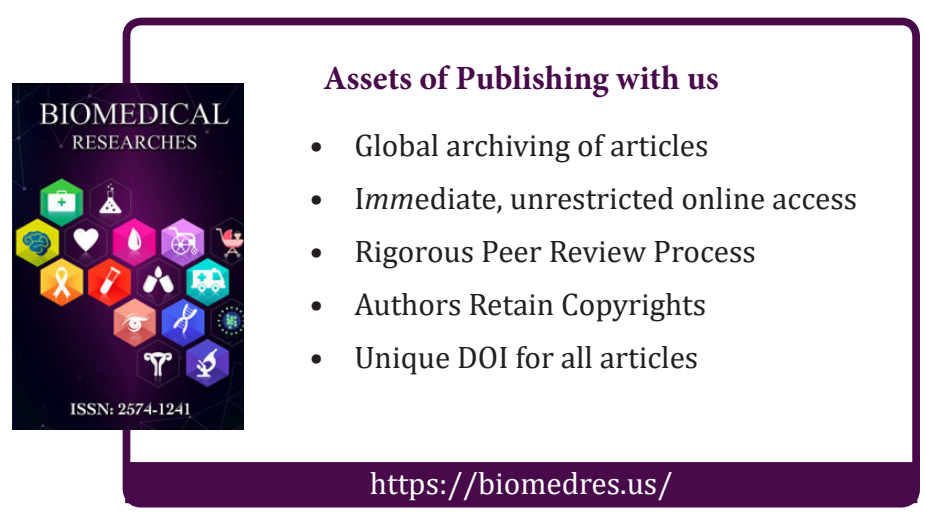

